\title{
Called To Lead
}

\author{
Jodi Dampeer-Moore ${ }^{1^{*}}$ and Gail Withers ${ }^{2}$
}

${ }^{1}$ Ed. D, MSN, RN, Faculty, College of Health Professions, Western Govonors University, USA.

${ }^{2}$ DNP, RN, APRN, Program Manager, College of Health Professions, Western Govonors University, USA.

Received: April 25, 2018; Accepted: April 26, 2018; Published: April 27, 2018

*Corresponding author: Jodi Dampeer-Moore, Faculty, College of Health Professions, Western Govonors University, USA; E-mail:- jdampeer@hotmail.com

\section{Editorial}

Promoting nursing leadership is one of the six categories of action items noted in the Future of Nursing: Leading Change, Advancing Health [5]. With the shared goal of improving health, nurses at all levels of education, experience, and current practice are needed to serve on committees, task forces, boards, etc. where healthcare issues are being discussed and/or decided. Leadership does not always come with a title; running a code as a staff nurse, chairing a committee for your state nurses association, being a peer trainer for new equipment, etc. are just a few examples of nurses as leaders.

How does a nurse become a leader? Behavioral Theory focuses on behaviors which can be transformed to develop a leader, whereas others e.g. Great Man Theory, suggests that leaders are born with leadership traits. Additionally, some believe in a combination of one having set of innate leadership traits that with education and experience can be exhibited as leadership [2, 3, 4]. This discussion is based on the premise that leadership skills can be learned. Nurses who are interested in a position of leadership or are interested in enhancing their professional growth can acquire leadership skills through either formal or informal training.

Leadership can be informally developed through mentoring [8]. Observing one or many demonstrating leadership skills is a great way to learn. Even observing examples of poor leadership can be helpful. Reflection of the observation experience through discussion with a trusted mentor is important. A mentor can help provide insight into how a process or task was properly managed through leadership, or, improperly managed. Further development occurs when the mentee performs a leadership role, selfreflects and then discusses the experience with the mentor to identify what went well and areas for improvement.

Formal mentoring has been the cardinal technique for teaching new employees their role. This method is instrumental in directing employees on learning the institutional policies and process, assisting with specific tasks and keeping the mentee on a solid path for professional development [7]. Utilizing a mentor who works in a similar leadership position has been key for success. One important aspect of mentoring is for the mentee to have access to the mentor after the training period is over for continued guidance and support.
Another method can be to acquire an advanced degree in leadership or complete a leadership certificate program. Many organizations are requiring individuals to have advanced degrees to be considered for an upper management or leadership role. Over the last several years there have been multiple programs created that focus on leadership.

Leadership education and immersion experiences are available through various nursing organizations. For example, the American Nurses Association (ANA) features recommended books and multiple online courses for CEs and the National League for Nursing (NLN) has developed opportunities to gain leadership skills through coursework, workshops, seminars and webinars $[1,6]$.

Nurses who are interested in advancement within their organization should reach out to their direct manager and inquire about such programs. It is extremely important for nurses to seek out these opportunities even if they are not interested in attaining a leadership position as the additional knowledge obtained can only complement one's own professional development.

Whether you want to improve or enhance leadership skills in your current position, enhance those skills for a new leadership position or to advance to the next level of leadership, there are many resources to help you get there. We as nurses should not only position ourselves for change, but also be active participants or leaders to ensure our practices reflect our mission to serve and protect our communities.

\section{References}

1. American Nurses Association.

2. Behavioral Theories of Leadership.

3. Thomas Carlyle. Great Man Theory. 1840;

4. Hyachith B. The Edge of Leadership: A Leader's Handbook for Success. MBA Caribbean Organization. 2015;

5. Institute of Medicine. The Future of Nursing: Leading Change, Advancing Health. Washington, DC. National Academic Press. 2011;

6. National League for Nursing.

7. Sonnino R. Health care leadership development and training: progress and pitfalls. Journal of Healthcare Leadership. 2016;8:19-29. Doi:10.2147/JHL.S68068

8. Zachary L. The Mentor's Guide: Facilitating Effective Learning Relationships, 2nd Edition. San Francisco, CA: Jossey-Bass. 2012; 